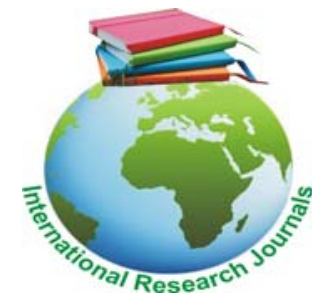

\title{
Haemostatic effect of methanolic stem bark extract of anacardium occidentale $L$. in male albino rats
}

\author{
Arokoyo $\mathrm{DS}^{1}$, Bamidele $\mathrm{O}^{2}$, Babatunde $\mathrm{LD}^{3}$, Adebisi $\mathrm{O}^{4}$ \\ Department of Physiology, Bowen University, Iwo, Osun State, Nigeria \\ Corresponding author's email: dennisarokoyo@yahoo.com
}

\begin{abstract}
Anacardium occidentale $L$. stem bark has been reported locally to stop tooth bleeding. However, scientific report on this assertion is relatively scanty. This study was therefore conducted to scientifically investigate the possible haemostatic effect of methanolic stem bark extract of Anacardium occidentale $L$. using albino rat as a model. Twenty four (24) albino rats weighing 110 to $160 \mathrm{~g}$ were divided into four groups of six (6) rats each. Control group received $10 \mathrm{ml} / \mathrm{kg}$ of vehicle (normal saline) while Group I, II, and III served as the experimental groups and were given 100,200 and $400 \mathrm{mg} / \mathrm{kg}$ of the methanolic stem bark extract of Anacardium occidentale $L$. intraperitoneally once a day for two weeks. In all groups, the blood samples were obtained by cardiac puncture under diethyl ether anaesthesia to determine prothrombin time, clotting time, activated partial thromboplastin time and platelet count. A skin puncture was made quickly using disposable lancet to determine bleeding time. The results obtained revealed that methanolic leaf extract of A. occidentale significantly decreased $(p<0.05)$ the bleeding time, prothrombin time, clotting time and activated partial thromboplastin time respectively in a dose dependent manner. In contrast, platelet count significantly increased $(p<0.05)$. The study suggests that methanolic stem bark extract of Anacardium occidentale $L$. possesses haemostatic activities, justifying its use to stop bleeding traditionally.
\end{abstract}

Key words: Anacardium occidentale, bleeding time, prothrombin time, clotting time, activated partial thromboplastin time, platelet count, haemostasis, albino rats.

\section{INTRODUCTION}

Plants of various origins have been exploited effectively over many generations for therapeutic purposes (World Health Organization, 2002). The selection procedure was often haphazard to the extent that some valuable errors are caused. Thus, the discard or acceptance of such plant depends on it being beneficial or hazardous (Farnsworth, 1989). In the last 20 years, the interest in medicinal plants has increased together with the number of investigations into their biological effects on human beings and animals (Veiga et al.2005).

Among the plants widely used for therapeutic purposes is the Anacardium occidentale L. species. Anacardium occidentale $\mathrm{L}$. belongs to the family Anacardiaceace, native to Brazil, having great economic and medicinal value and which is composed of some 60 to 74 genera and 400 to 600 species. It is characterized by a leafy tree. The largest cashew tree in the world covers an area of about 7,500 square meters (Pundir et al., 1964). The Anacardium actually refers to the shape of the fruit which looks like an inverted heart (ana means 'upwards' and cardium means 'heart') (Correa, 1978).

Its English name- Cashew is derived from the Portuguese name for the fruit of the cashew tree, Caju, which itself is derived from the indigenous Tupi name, acaju which means 'nuts that produces itself' (Barcelos et al., 2007). It is originally native to Northeastern Brazil especially the Amazon and can also be found in Southeast Asia, Central and South America, parts of Africa and Vietnam (Santos et al., 2007)

Several reports exist demonstrating the use of the leaves, stem bark, stem and fruits of this species in popular medicine. The bark is astringent and rich in tannin, which would justify its popular indication for healing wounds. It is also indicated for combating hypertension, in the treatment of gastric disturbances and for anti-inflammatory (Mota et al., 1985) and bactericidal 
treatment (Akinpelu, 2000). An infusion of cashew stem bark presents analgesic and aphrodisiac properties and is also indicated against intestinal cramps, peptic ulcers, asthmas and bronchitis. Preclinical studies of the metabolites isolated from the bark of this tree species demonstrated antipyretic action for anacardic acid and anti-inflammatory activity (Eichbaum, 1988). The $A$. occidentale bark is also used in Ayurvedic medicine to detoxify snake bite as well as for fevers; a laxative to rid intestinal parasites and to treat diabetes (Rajesh et al., 2009; Thomson, 2004).

Interest in this study was stimulated by local report of the usefulness of $A$. occidentale in treating tooth bleeding and toothache in Nigeria by traditional healers. However, there is a dearth of research publication to support the folkloric use of the plant in enhancing haemostasis. Therefore, the present work was carried out to scientifically investigate the possible haemostatic potentials of methanolic stem bark extract of Anacardium occidentale $\mathrm{L}$. in albino rats.

\section{MATERIALS AND METHODS}

\section{Care and Management of Animals}

A total of 24 male Wistar albino rats with weight range of 110-160g purchased from a rat breeder in Patako area in Ibadan, Oyo State, Nigeria were used in this study. The animals were kept in cages under standard conditions (temperature, $25 \pm 2^{\circ} \mathrm{C}, 12$ hours light and 12 hours dark cycle) in the animal house of the Physiology Department, Faculty of Basic medical science, Bowen University, Iwo, Osun State, Nigeria. All the animals were fed with commercially formulated rat feed and water ad libitum. After randomization into various groups, the rats were acclimatized for a period of 2 weeks before the initiation of the experiment. Their cages were cleaned of waste daily. All procedures involving the use of animals in this study complied with the guiding principles for research involving animals as recommended by the declaration of Helsinki and the Guiding principles in the care and use of animals (World Medical Association, 2002).

\section{Plant material}

Fresh stem-bark of A. occidentale was collected around some parts of Bowen University, Iwo Osun state. The botanical identification and authentication was done by the Chief Herbarium Officer of the

Department of Biological Sciences, Bowen University, Iwo, Osun State, Nigeria. The stem-barks were washed in tap water and shade-dried after which they were reduced into fine powder by grinding and soaked for $72 \mathrm{~h}$ in methanol $(70 \% \mathrm{v} / \mathrm{v}, \mathrm{BDH})$ at room temperature. It was then filtered with Whatman No. 1 filter paper to separate the filtrate from the residue. The filtrate was then concentrated using a rotary vacuum evaporator to obtain the solid mass. The solid extract was then re-dissolved in normal saline and stored in capped bottles in a refrigerator at $4^{\circ} \mathrm{C}$ until required.

\section{Experimental design}

Twenty-four animals were randomly divided into four groups of six rats each as follows:

\section{Control group}

In this group, six rats were used. Each rat received $1 \mathrm{ml}$ of normal saline intraperitoneally for a period of two weeks.

\section{Group I (Low dose)}

There were six rats in this group and each rat received $100 \mathrm{mg} / \mathrm{kg}$ of methanolic stem-bark extract of $A$. occidentale intraperitoneally for a period of two weeks.

\section{Group II (Medium dose)}

Also, there were six rats in this group and each rat received $200 \mathrm{mg} / \mathrm{kg}$ of methanolic stem-bark extract of $A$. occidentale intraperitoneally for a period of two weeks.

\section{Group III (High dose)}

It contains six rats and each rat received $400 \mathrm{mg} / \mathrm{kg}$ of methanolic stem-bark extract of $A$. occidentale intraperitoneally for a period of two week

\section{Collection of blood sample}

At the end of the experiment, the rats were anaesthetized with diethyl ether and blood samples were collected by cardiac puncture using disposable plastic syringes (with needles) into sample vials containing sodium citrate in ratio 1:9 with blood. Only blood used for clotting time were collected in anticoagulant- free vials.

\section{Sample analysis}

\section{Determination of bleeding time}

This was determined using a modified Duke method (Ochei and Kolhatkar, 2000). A skin puncture was made quickly, using disposable lancet, and the stop watch was started as soon as bleeding started. The puncture was dabbed with filter paper every 15 seconds until the paper 
was no longer stained red with blood. Bleeding time was then taken as the time when the blood stopped flowing from the puncture.

\section{Determination of clotting time (Lee-White Method)}

Blood was taken directly from the heart (to avoid contamination with tissue thromboplastin) $0.8 \mathrm{mls}$ from each rat. $0.2 \mathrm{mls}$ of blood was then delivered into four glasss test-tubes that had previously been warmed and maintained at $37^{\circ} \mathrm{C}$ and the tubes immediately placed in a $37^{\circ} \mathrm{C}$ water bath to mimic the temperature of the internal environment. The stop watch was started immediately the blood was delivered into the glass test-tubes and the tubes were continually tilted at 40-second intervals (until blood in them stopped flowing when tilted at angle of $90^{\circ}$ ), starting with the first, to see and note when the blood clotted. The clotting time was taken as the average of the times blood clotted in the four tubes.

\section{Determination of prothrombin time (PT)}

Blood was collected into sample vials containing $3.2 \%$ sodium citrate (as specified in the PT test kit used) in the ratio 1:9 with the blood sample. The blood was then centrifuged at $1000 \mathrm{~g}$ for 15 minutes to obtain platelet poor plasma. Thromboplastin PT-S was placed in the water bath at $37^{\circ} \mathrm{C} ; 0.1 \mathrm{ml}$ of test plasma was also put into a test-tube and placed in the water bath to prewarm to $37^{\circ} \mathrm{C}, 0.2 \mathrm{ml}$ of warmed thrmboplastin PT-S was then forcibly added to the test plasma and the stop watch was started. The tube was tilted repeatedly until a clot was formed and the time taken for clot to form was noted. This was repeated for all samples. Particular precaution was taken to perform test within three hours of blood collection since the labile factor deteriorates quickly at room temperature.

\section{Determination of activated partial thromboplastin time (APTT)}

Blood was collected into sample vials containing $3.2 \%$ sodium citrate (as specified in the APTT test kit used) in the ratio 1:9 with the blood sample. The blood was then centrifuged at $1000 \mathrm{~g}$ for 15 minutes to obtain platelet poor plasma. The plasma was stored in a plastic tube. Calcium chloride was pre-warmed at $37^{\circ} \mathrm{C}$ for 10 minutes. $0.1 \mathrm{ml}$ of blood sample was placed into a tube and warmed at $37^{\circ} \mathrm{C}$ for 2 minutes. $0.1 \mathrm{ml}$ of APTT-S reagent was added to the sample and incubated for 3 minutes also at $37^{\circ} \mathrm{C}$. $0.1 \mathrm{ml}$ of the pre-warmed calcium chloride was finally added and the stop watch was started. The tub was tilted repeatedly until a clot was formed and the time taken for clot to form was noted. This was repeated for all samples. Particular precaution was also taken to perform this test within three hours of blood collection since the labile factor deteriorates quickly at room temperature.

\section{Determination of Platelet Count}

Blood sample was collected into vials. The whole blood was diluted with $1 \%$ ammonium oxalate solution. The blood was mixed thoroughly with the oxalate solution. The dilution was prepared using the leukocyte/platelet Unopette system. It was then left to stand (incubate) for 10 minutes to allow the erythrocytes to haemolyse. After the incubation period, the dilution was mounted on a haemocytometer. The cells were allowed to settle and were viewed under the microscope. The number of platelet was then calculated per $\mu \mathrm{L}\left(\times 10^{\wedge} \mathrm{g} / \mathrm{L}\right)$ of blood.

\section{Determination of Astringent Properties}

Two tubes were used for the experiment- one for the test and the other for control. The test tube contained $1 \mathrm{ml}$ of stem- bark extract and the control test contained $1 \mathrm{ml}$ of distilled water. $4 \mathrm{ml}$ of milk was added in each tube. They were homogenized and allowed to stand for 3 minutes, then centrifuged for 1 minute at $3000 \mathrm{rpm}$. The presence or absence of pellets was noted.

\section{Statistical analysis}

The results were analyzed using one way analysis of variance (ANOVA) and expressed as mean \pm SEM. Data was further subjected to LSD Post hoc test and differences. The results were considered significant at $p$ values of less than 0.05 .

\section{RESULTS}

\section{Bleeding time}

The extract decreased bleeding time in rats of the experimental group in comparison with the control group. The bleeding time was measured in minutes. Mean bleeding time of control group was $4.25 \pm 0.027 \mathrm{~min}$ and $3.22 \pm 0.038,2.35 \pm 0.057$ and $1.18 \pm 0.033 \mathrm{~min}$ for groups 1,2 and 3 respectively (Figure 1 ). The analysis showed that this decrease was significant $(P<0.05)$ in all experimental groups when compared independently with the control. The effect was most significant in the Group III which received the highest dose of the methanolic stem-bark extract of $A$. occidentale. 


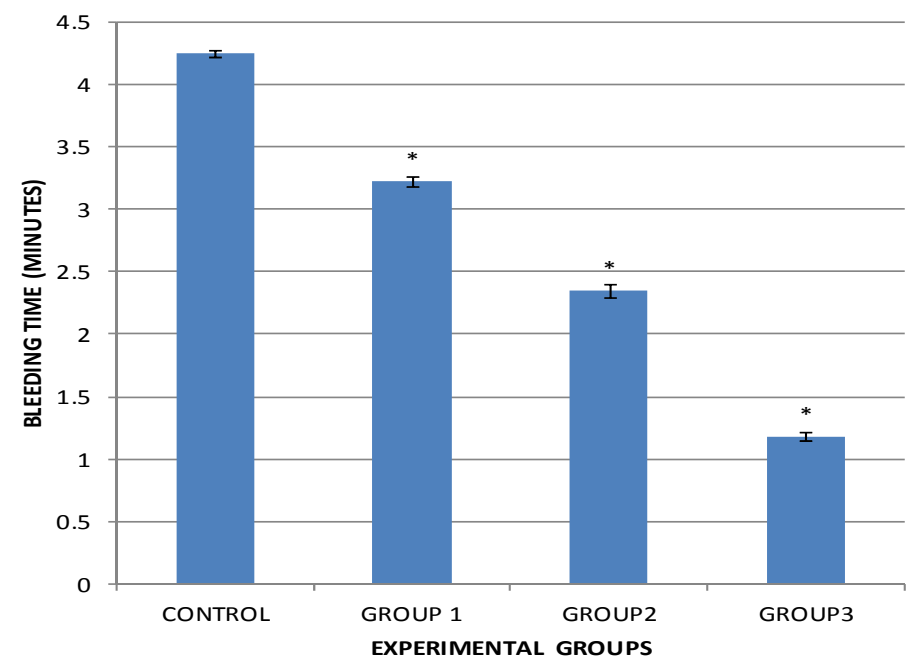

BLEEDING TIME

Figure 1: Bar chart showing changes in bleeding time in the groups

Values are expressed as mean \pm S.E.M. ${ }^{*} P<0.05,(n=5)$

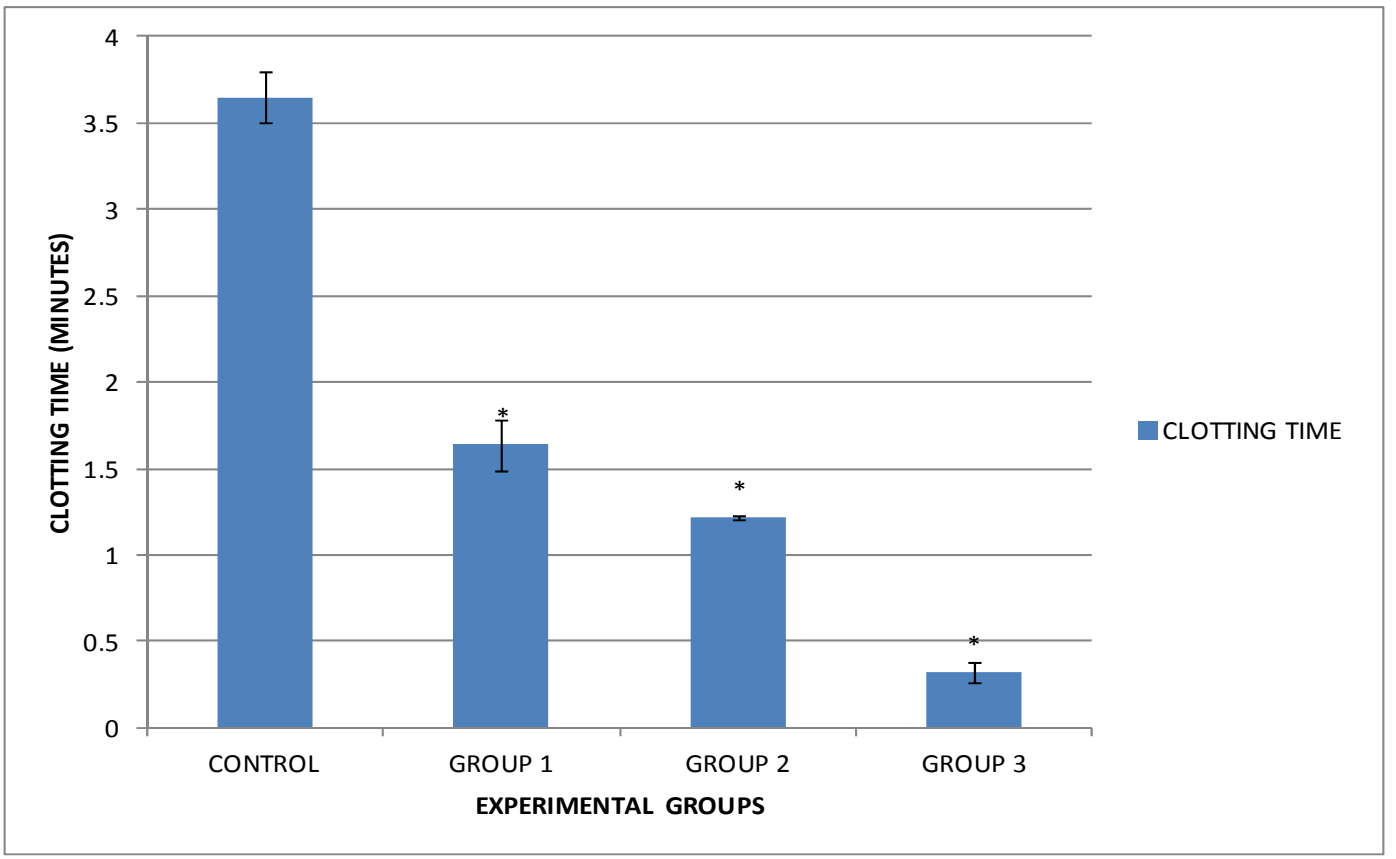

Figure 2: Bar chart showing changes in clotting time in the groups.

Values are expressed as mean \pm S.E.M. ${ }^{*} P<0.05,(n=5)$

\section{Clotting time}

There were decreases in clotting time of test groups when compared to control group as shown in Figure 2.
The mean value of control was $3.65 \pm 0.148$ mins while those of group I, II and III were $1.64 \pm 0.147$ mins, $1.22 \pm$ 0.010 mins and $0.32 \pm 0.058$ mins for respectively. The analysis showed that these decreases were statistically 


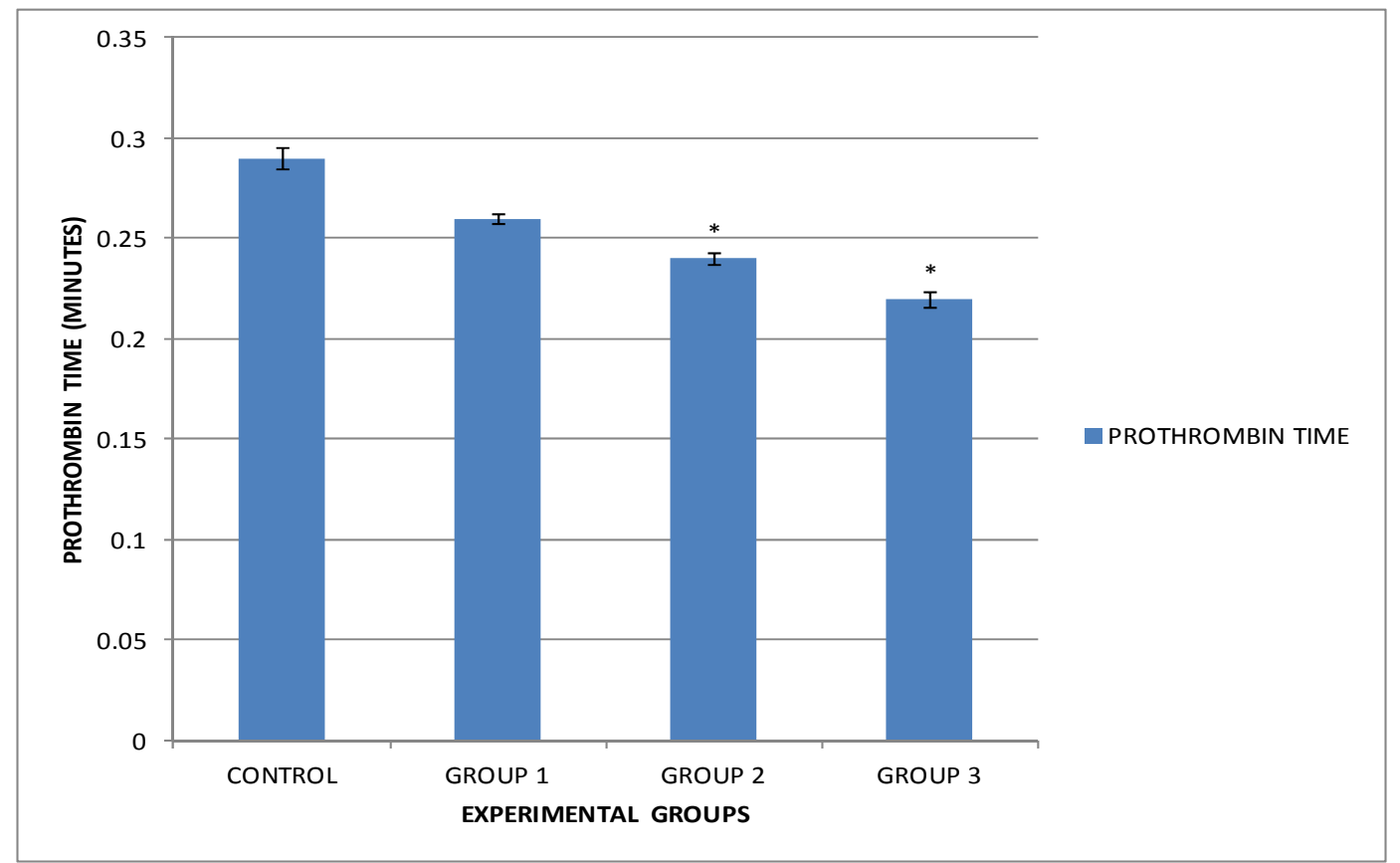

Figure 3: Bar chart showing changes in prothrombin time in the groups

Values are expressed as mean \pm S.E.M. * $P<0.05,(n=5)$

significant $(\mathrm{P}<0.05)$.

\section{Prothrombin time}

The mean value of prothrombin time was $0.29 \pm 0.005$ mins in control group, $0.26 \pm 0.002$ mins (group I), $0.24 \pm$ 0.003 mins (group II) and $0.22 \pm 0.004$ mins (group III) as shown in Figure 3. There were significant decreases $(p<$ 0.05 ) in prothrombin time in the experimental groups compared with the control group. The decreases were dose dependent with most significant decrease in group III.

\section{Activated partial thromboplastin time}

Activated partial thromboplastin times obtained in the test groups were significantly different from that of the control group. The mean value of control group was $0.20 \pm$ 0.004 mins while $0.17 \pm 0.003$ mins, $0.15 \pm 0.003$ mins and $0.12 \pm 0.003$ mins were mean values obtained for groups I, II and III respectively. The mean values are depicted in the Figure 4 below.

\section{Platelet count}

Platelet count was also decreased by increasing the dosage of the extract. The mean value of control group was $113600.0 \pm 509.90$ per $\mu \mathrm{L}$ while the mean values of group I, II, II were $144200.0 \pm 860.23$ per $\mu \mathrm{L}, 146800.0 \pm$ 489.90 per $\mu \mathrm{L}$ and $188500.0 \pm 7880.35$ per $\mu \mathrm{L}$ respectively. There were statistical difference between the test groups and the control group as shown in the Figure 5 below.

\section{Astringent properties}

The test tube containing the methanolic stem-bark extract of $A$. occidentale showed the presence of pellets after the experiment indicating a positive astringency test, thus implying that it contained astringent properties.

\section{DISCUSSION}

Many indigenous tribes around the world have long suspected that this ubiquitous, perennial plant ( $A$. occidentale) might have medicinal wound healing properties. The $A$. occidentale stem bark extract have been shown to enhance natural resistance and recuperative powers of the body (Singh et I., 1991).

In this present study, administration of the $A$. occidentale stem extract effectively reduced bleeding time in the experimental rats. Bleeding time is a sensitive test of endothelial and platelet function and platelet number (Cheesbrough, 2000) hence it is especially dependent on platelet function and number. Thus the 


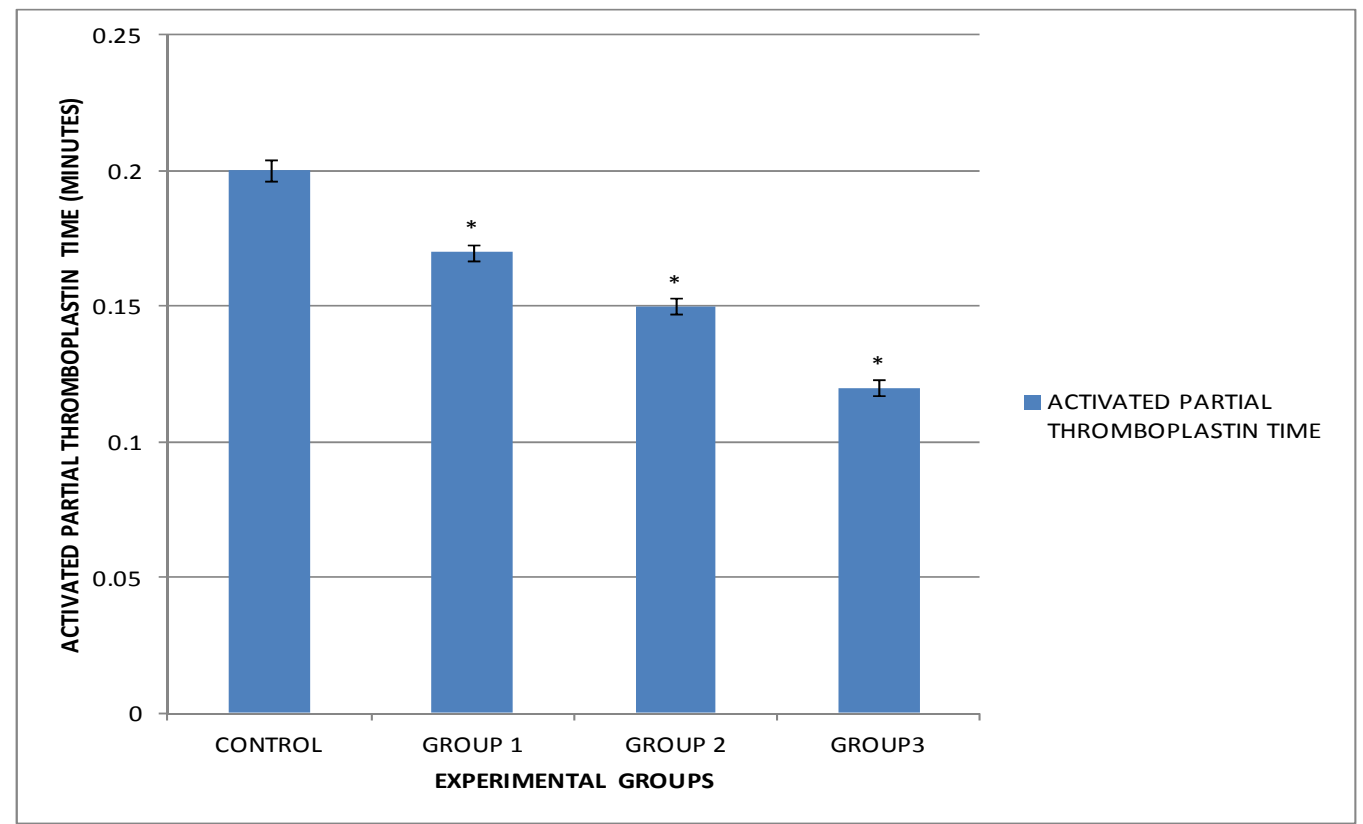

Figure 4: Bar chart showing changes in activated partial thromboplastin time in the groups Values are expressed as mean \pm S.E.M. ${ }^{*} P<0.05,(n=5)$

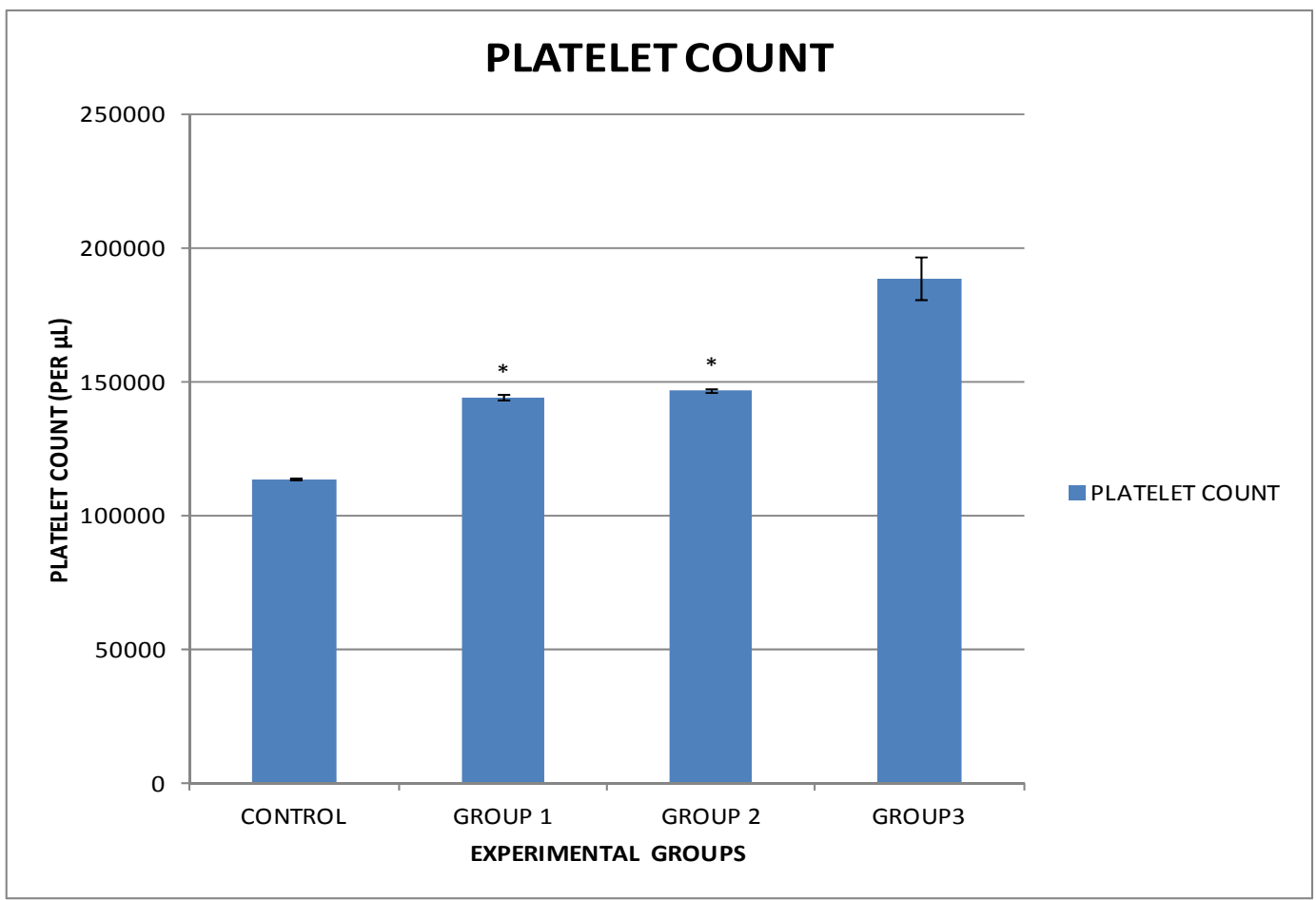

Figure 5: Bar chart showing changes in platelet count in the groups

Values are expressed as mean \pm S.E.M. ${ }^{*} P<0.05,(n=5)$

activity of extract in decreasing bleeding time may result from an increase in platelet number. This consequently is in agreement with the results obtained from the platelet count which shows an increase in the platelet in the test groups. The platelet count increased effectively after administration of the extract. This could be as a result of 
the Vitamin $k$ which has been shown to effectively increase platelet number (Ananyeva et al., 2003) or Vitamin $C$ which is widely believed to also play a part in platelet number but without conclusive evidence.

Clotting time is a qualitative measurement of factors involved in the intrinsic pathway (Ochei et al., 2000). Therefore, deficiency in the factors of the intrinsic pathway (I, II, V, VIII, IX, X, XI, and XII) will affect clotting time. From results obtained, there was significant decrease in clotting time, reflecting that there was an increase in one or more of the clotting factors involved in the intrinsic pathway. This can be traced to the presence of Vitamin K as estimated by Visalli et al (1999) in the $A$. occidentale stem-bark extract as it has been shown to stimulate liver production of factors II, IX and X (Stamatoyannopoulos, 2001). These results correlate with the report by Okoli et al. (2007) on the haemostatic activities of the leaf extract of Aspilia Africana which arrested bleeding from fresh wounds by reducing both bleeding and clotting times in the Aspilia Africana leaf and Bamidele et al (2010) on the haemostatic activities of the leaf extract of Ageratum conyzoides which reduced bleeding, clotting and prothrombin times in rats to Vitamin $\mathrm{K}$ present in the extracts.

The results obtained also showed significant decrease in prothrombin time. Since prothrombin time is a screening test for the extrinsic clotting system, that is factor VII and can also detect deficiencies of factors prothrombin, $\mathrm{V}, \mathrm{X}$ and fibrinogen (Cheesbrough, 2000), it follows then that the decrease in prothrombin time by the extract may be a result of increase in the concentration of prothrombin or one of the other extrinsic clotting factors. Vitamin $\mathrm{K}$ (present in the stem bark) has been shown to play a major role in essential the liver formation of the factors of the extrinsic pathway- factor prothrombin and factor X (Stamatoyannopoulos, 2001). This could therefore mean the presence of the Vitamin K (Visalli et al, 1999) is responsible for the reduced prothrombin time.

Activated partial thromboplastin time (APTT) was also decreased significantly as observed from the results. This is a measure of the integrity of the intrinsic pathway. As the results points out the decrease in the activated partial thromboplastin time, it also suggests there was an increase in one or more of the factors of the intrinsic pathway aided by the presence of Vitamin K.

Astringent test came out positive. The astringent test is a measure of the presence of chemical compounds that tend to make body tissues shrink or constrict. The stem bark extract of the A. occidentale showed astringency, this could be as a result of the presence of tannins. This is in agreement with earlier work reported by Olaleye et al (2007) and Ojezele et al (2013) that the A.occidenatle had high concentration of tannins.

Metabolites found in the A. occidentale include flavinoids, alkaloids, saponins and tannins which are biologically active (Olaleye et al., 2007). Tannins have been implicated in the haemostatic activity of plants where they arrest bleeding from damaged or injured vessels by precipitating proteins to form vascular plugs (Okolie et al., 2007 and Bamidele et al., 2010).

Vitamin $\mathrm{K}$ which plays an important role in the synthesis of clotting factor II (prothrombin), VII, IX, X, is continually synthesized in the intestinal tract by bacteria and thus can be affected by gastrointestinal disorders.

These properties of the plant may have been responsible for the positive haemostatic activity of the stem bark extract, though other mechanism may be responsible.

\section{CONCLUSION}

The present results indicate that the methanolic bark extract of A. occidentale effectively decreased bleeding, clotting prothrombin and activated partial prothrombin time and increased platelet count with the extract exhibiting astringency. This shows an improvement in the coagulatory mechanism with $A$. occidentale extract compared with normal saline treated control; hence, this indicates a positive haemostatic activity of the stem bark. Thus, the A. occidentale stem bark could be useful in wound management affirming the logic behind its usage in traditional medical practice.

\section{REFERENCES}

Akinpelu DA (2000). Antimicrobial activity of Anacardium occidentale. Fitoterapia 72, 286-287.

Ananyeva NM, Saenko EL, Shima M (2003): The future of recombinant coagulation factors. J Thromb Haemost 1:922.

Bamidele O, Akinnuga AM, Anyakudo MMC, Ojo OA, Ojo GB, Olorunfemi JO, Johnson OP (2010) Haemostatic Effect of Methanolic Leaf Extract of Ageratum conyzoides in Albino Rats. Journal of Medicinal Plant Research, 4(20): 2075-2079.

Barcelos G, Shimabukuro F, Maciel M, Clus I (2007). Genotoxicity and antigenotoxicity of cashew (Anacardium occidentale L.) in V79 cells. Toxicol. In Vitro, 21: 1468-1475.

Cheeseborough (2000). District Laboratory Practice in Tropical Countries (Part 2). Low price edition: Cambrige University Press.

Correa M.P (1978). Dicion'ario de plantas 'uteis do Brasil. Minist'erio da Agricultura, IBDF: Rio de Janeiro, p. 55 (in Portuguese).

Eichbaum FW (1988). Biological properties of anacardic acid (Opentadecadienyl-salicylic acid) and related compounds. Mem'orias do linstituto Butaña 19, 119-133.

Farnsworth NR (1989). Screening Plants for NewMedicine. In: Wilson, E.O. (Ed.), Biodiversity. Partll. National Academy Press, Washington, pp:88-97.

Mota MLR, Thomas G, Barbosa F (1985). Anti-inflammatory actions of tannins isolated from the bark of Anacardium occidentale L. Journal of Ethnopharmacology 13, 289-300.

Ochei J, Kolhatkar A (2000) Medicinal Laboratory Science. Theory and Practise. Tata Mcgraw-Hill Pubishing Company Limited: New Delhi $2^{\text {nd }}$ Edition. PP 331-349

Okoli CO, Akah PA, Okoli AS (2007). Potentials of leaves of Aspilia Africana (Compositae) in wound care; an experimental evaluation.BMC Complementary and Alternative Med., $7: 24: 10.1186 / 1472$.

Olaleye MT, Kolawole A, Ajeje JO (2007): Antioxidant properties and Glutathione S Transferases inhibiting activity of A. Cordifolia leaf extract in Acetaminophen-induced liver injury. Iranian J. Pharmac Therapeu;6:63-66 
Rajesh KV, Sumathi CS, Balasubramanian V, Ramesh N (2009). Elementary Chemical Profiling and Antifungal Properties of Cashew (Anacardium occidentale L.) Nuts. Botan. Res. Internation., 2: 253257.

Santos RP, Santiago AAX, Gadelha CAA, Cajazeiras JB, Cavada BS, Martins JL, Oliveira TM, Bezerra GA, Santos RP, Freire VN (2007). Production and characterization of the cashew (Anacardium occidentale L.) peduncle bagasse ashes. J. Food Eng.,79: 14321437.

Singh N, Verma P, Mishara N, Nath R (1991): A comparative evaluation of some antistress agents of plant origin. Ind J Pharmac; 21: 99

Stamatoyannopoulos G (2001). The Molecular Basis of Blood Disease, 3rd ed. WB Saunders, 2001.

Thomson Healthcare (2004). PDR for herbal medicines. 3rd edition Thomson PDR, New Jersey, U.S.A., pp.165-166.

Veiga JVF, Maciel MAM, Pinto AC (2005). Plantas medicinais: cura segura? Quim Nova 28: 519-528.

Visalli N, Cavallo MG, Signore A, Baroni MG, Buzzetti R, Fioriti E, Mesturino C, Fiori R, Lucentini L, Matteoli MC, Crino A, Corbi S, Spera S, Teodino C, Paci F, Amoretti R, Pisano L, Suraci C, Multari
G, Sulli N, Cervon M, De Mattia G, Faldetta MR, Boscherini B, Pozzill P (1991): A multi-centre randomized trial of two different doses of nicotinamide in patients with recent-onset type 1 diabetes (the IMDIAB vi) Diabet Metab Res Rev; 15: 181-185.

World Medical Association (2002). Americal Physiological Society.Guiding principles for research involving animals and human beings. Am. J. Physiol. Reg. Integr. Comp. Physiol., 283: 281-283

Varghese TM, Pundir YPS (1964). Anatomy of the pseudocarp in Anacardium occidentale. Proceedings: Plant Sciences, 59(5),252258 